\title{
Cascade Feed Forward Neural Network-based Model for Air Pollutants Evaluation of Single Monitoring Stations in Urban Areas
}

\author{
Giacomo Capizzi, Grazia Lo Sciuto, P. Monforte and Christian Napoli
}

\begin{abstract}
In this paper, air pollutants concentrations for $\mathrm{NO}_{2}$, $N O, N O x$ and $P M 10$ in a single monitoring station are predicted using the data coming from other different monitoring stations located nearby. A cascade feed forward neural network based modeling is proposed. The main aim is to provide a methodology leading to the introduction of virtual monitoring station points consistent with the actual stations located in the city of Catania in Italy.
\end{abstract}

Keywords-neural networks, Synthetic Aperture Radar (SAR), mahalanobis distance

\section{INTRODUCTION}

A IR quality has emerged as a major factor affecting the life quality in urban areas, in particular in densely populated cities and industrialized areas. The urban air quality depends on gases, dust particles, fumes or smoke, and liquid droplets from fuel combustion introduced into the atmosphere changing the natural balance, damaging effects on living things. Moreover the air pollution contributes to the global warming problem. In fact, it is essential to provide air quality monitoring systems which continuously measure the amount of air pollutants in urban areas, as well as the safety of air, and to develop a strategic plan that involves various modeling techniques, analysis of chemical and physical parameters associated with climate change. Nowadays, mathematical methods and tools such as soft-computing techniques provide forecasting capabilities, thus offering the opportunity to take preventive measures that would reduce the discharge of pollutants and particles due to traffic. This is realised by operating restricted traffic zones in many municipal towns and cities in Italy with the primary aim of reducing traffic congestion by charging vehicles.

A review of the literature reveals that artificial intelligence [1], PSO methods [2], swarm algorithms [3] and Artificial Neural Network (ANN) [4], [5] models have become

This work has been supported by project PRISMA PON04a2 A/F funded by the Italian Ministry of University and Research within PON 2007-2013 framework and by project PRIME within POR FESR Sicilia 2007-2013 framework.

G. Capizzi and G. Lo Sciuto are with the Department of Electrical, Electronics and Informatics Engineering University of Catania, Viale A. Doria 6 , 95125 Catania, Italy, (email: gcapizzi@diees.unict.it, glosciuto@dii.unict.it).

P. Monforte is with the Department of of Biological, Geological and Environmental Science University of Catania, Catania, Italy, (email gcapizzi@diees.unict.it).

C. Napoli is with the Department of Mathematics and Informatics, University of Catania, Viale A. Doria 6, 95125 Catania, Italy, (email napoli@dmi.unict.it). a promising tool for air quality prediction [6], [7]. Moustafa [8] has proposed fuzzy neural schemes for forecasting and classifying $\mathrm{NO}_{2}$ and $\mathrm{SO}_{2}$ emissions over urban areas based on measured emissions over industrial areas. Hooyberghs et al. [9] describe the development of a neural network tool to forecast the daily average PM10 concentrations. Prybutok [10] has developed a neural network model for forecasting daily maximum ozone levels and comparing with two conventional statistical models, regression and Box-Jenkins ARIMA by Mitchell et al [10]. Gavin Cawleyd et [11] present the most extensive evaluation of $\mathrm{NN}$ models currently available for the prediction of urban $\mathrm{NO}_{2}$ and PM10 concentrations, also including a statistical LIN and a DET. Kolehmainen et al. [12] evaluate and compare univariate (linear interpolation, spline interpolation) and multivariate methods (regression-based imputation, the multivariate nearest neighbouring method, the self-organizing map and the multi-layer perceptron) for missing data imputation in air quality data sets. Dorling [13] has shown that MLP neural networks can accurately model the relationship between local meteorological data and $\mathrm{NO}_{2} / \mathrm{NO} x$ concentrations in an urban environment.

In this paper, air pollutants concentrations for $\mathrm{NO}_{2}, \mathrm{NO}$, $N O x$ and $P M 10$ of a single monitoring station are predicted using the data coming from other different monitoring stations proposing a cascade feed forward neural network based modeling. The goal of this study is the construction of models, using cascade feed forward neural network based modeling (CFNNs) [14], [15] which give the possibility of the evaluation of air pollution index for $\mathrm{NO}_{2}, \mathrm{NO}, \mathrm{NOx}$ and $\mathrm{PM} 10$ in a site enclosing a monitoring station by exploitation of the other measured data for different measuring sites. The site of the considered measurement station is selected to represent a typical residential area with high traffic influences in the city of Catania. Data come from some examined stations in the area of interest. Fig. 1 indicates the locations of the monitoring stations.

Catania is an urban area with high density of habitants and has the same air pollution problems as other big cities in the world. These problems are getting worse due to bad city planning and the city topographical features. However, the geography of this city aids the dispersion of air pollutants. The main air pollutants emissions is due to transport vehicles and industrial actvities.

The input of the neural network are data concentrations of air pollutions of different area of the city of Catania. 
The data of the concentration of pollutants are used for training the network and are related to 240 days in 2012. The performance of the CFNN model is validated using the real observation data. We collected more data for training, designed experiments on various CFNN to test the influences on model performance. The number of hidden layers and the number of neurons in each hidden layer are mainly determined by trial and error.

The group of data, the training set, by which we trained the CFNN concerned period in the year 2012. Validation set, the group of data, given to the network still in the learning phase, was $20 \%$ of the training set for the above mentioned networks. Simulation results reveal the models' capability for the air pollutants evaluation.

\section{The Problem of Air Pollution Monitoring SySTEMS IN THE CITY OF CATANIA (ITALY)}

Atmospheric air pollution in urban areas is a growing problem. In cities where geographical and meteorological conditions allow poor circulation, and with a large population living, so as in a not well planned city harmful health effects are well established. Then an air pollution monitoring and control is needed. In recent years the city of Catania has focused on reducing its environmental impact because is defined as a highly urban area with a considerable traffic load in the city.

Catania is one of the metropolitan city in Italy densely populated, is characterized by effects of Airport International Catania and high motorization; its population is declared as over inhabitants 1885.9 per square kilometer. Many interesting factors play a fundamental role in the variability of air flow: morphological and topographical conditions, the influence of volcanic passive degassing on air quality of Mt. Etna, the development of sea and land breeze circulation systems. The population of Catania and its vehicular traffic are concentrated within the city. In nearly every case, urban congestion translates into traffic congestion. Most of the people have automobiles (65,000 vehicles), motorcycles, motor scooters. But in addition to this routine urban transportation, for instance the vehicular pollution is considered to be the most significant sources of urban pollution from 6:00 p.m to 9:00 p.m in summer with significant peak of growing level of poisonous gases between 7:30 a.m and 9:30 a.m.

The monitoring station located in Librino's area defines Nitric oxide but it is readily converted in the air to nitrogen dioxide unlike what happens in the viale Vittorio Veneto, where only part of $\mathrm{NO}$ can turn into $\mathrm{NO}_{2}$ consuming almost all $\mathrm{O}_{3}$ available. Surprisingly enough, nitrogen dioxide $\mathrm{NO}_{2}$ presents a higher concentration in the part of area identified as Parco Gioeni, though it is not significantly exposed to traffic congestion, the oxidation reaction of $N O$ appears more efficiency. $\mathrm{NO}$ can also turn into $\mathrm{NO}_{2}$ by just reacting with $\mathrm{O}_{2}$, this is the cause of the smog and effect of sunlight.

The limit hourly value of $200 \mu \mathrm{g} / \mathrm{m}^{3}$ is not exceeded in the city of Catania, thus more intensive traffic and less ventilation condition, for concentrations between hourly mean value of $100 \mu \mathrm{g} / \mathrm{m}^{3}$ and annual average of $40 \mu \mathrm{g} / \mathrm{m}^{3}$ a concrete health
TABLE I

\begin{tabular}{cccc}
\hline \multicolumn{1}{c}{ Station } & Description & Altitude $(\mathbf{m})$ & Latitude/Longitude \\
\hline V.le V. Veneto & Heavy traffic & 38 & $37^{\circ} 30^{\prime} 56.83^{\prime \prime} N$ I \\
& & & $15^{\circ} 05^{\prime} 50.26^{\prime \prime} E$ \\
P.za A. Moro & Medium traffic & 76 & $37^{\circ} 31^{\prime} 32.95^{\prime \prime} N /$ \\
& & & $15^{\circ} 05^{\prime} 13.95^{\prime \prime} E$ \\
Parco Gioeni & Urban-backgr & \multirow{2}{*}{135} & $37^{\circ} 31^{\prime} 45.44^{\prime \prime} N /$ \\
& & $15^{\circ} 41^{\prime} 51.99^{\prime \prime} E$ \\
Librino & Light traffic & \multirow{2}{*}{71} & $37^{\circ} 29^{\prime} 03.47^{\prime \prime} N /$ \\
& & & $15^{\circ} 02^{\prime} 48.70^{\prime \prime} E$ \\
\hline
\end{tabular}

risk and quality of life is assumed. The anthropogenic contribution of $P M 10$ is due to vehicular traffic, it is not significant contribution of the very limited industrial emissions. The natural sources of particulate matter is contained in the desert sand transported by air masses from North Africa. This involves occasional exceedances of the daily level of $50 \mu \mathrm{g} / \mathrm{m}^{3}$

The network of air quality monitoring stations in Catania is designed and managed by Direzione Ecologia e Ambiente since 1992. Between 2009 and 2010 it is reduced instrumentation equipment, and a large number of monitoring stations according to the European Directives 2008/50/EC and this is evidenced by Legislative Decree No 155/2010, with obvious reason due to expensive sustainability of maintenance/repair.

To provide a methodology leading to the introduction of virtual monitoring stations points, consistent with the actual stations, would be highly advantageous as regards the spatial coverage of the territory, as in the case of a high number of stations could be achieved through a more efficient spatial relocation. The ability to take advantage of more virtual monitoring points can also facilitate the process of validation and consistency of the data recorded in the real monitoring stations. The realization of the forecasts virtual station becomes very important to municipal city offering multiple advantages both in economic point and management term. Therefore, the prediction model has aimed to extend the interactions between a limited number of real monitoring stations in order to obtain a larger number of virtual stations which allows a better spatial country planning, and reduction of aliasing space as a result.

In our study we have taken into account the concentrations of air pollution of two different monitoring stations located in Parco Gioeni and Viale Vittorio Veneto to estimate the concentrations of a third station, in the site of Piazza Moro, with the same operative conditions, orographic effect, traffic congestion, buildings and materials (see Fig. 1).

\section{Air Quality Monitoring And Measurement Stations In THE City of CATANia (ItAly): DATA AND Methodology}

The monitoring station, identified in Piazza Moro, has similar statistical estimation of the traffic congestion of areas where the other two gas monitoring stations are nearby located given the intermediate position. Then it is really possible to implement a forecasting model, based on the data of air pollutant concentrations, measured at nearby stations (Gioeni Park and Viale V. Veneto) so creating a virtual monitoring station. A monitoring program for PM10, NO2, NO, NOx 


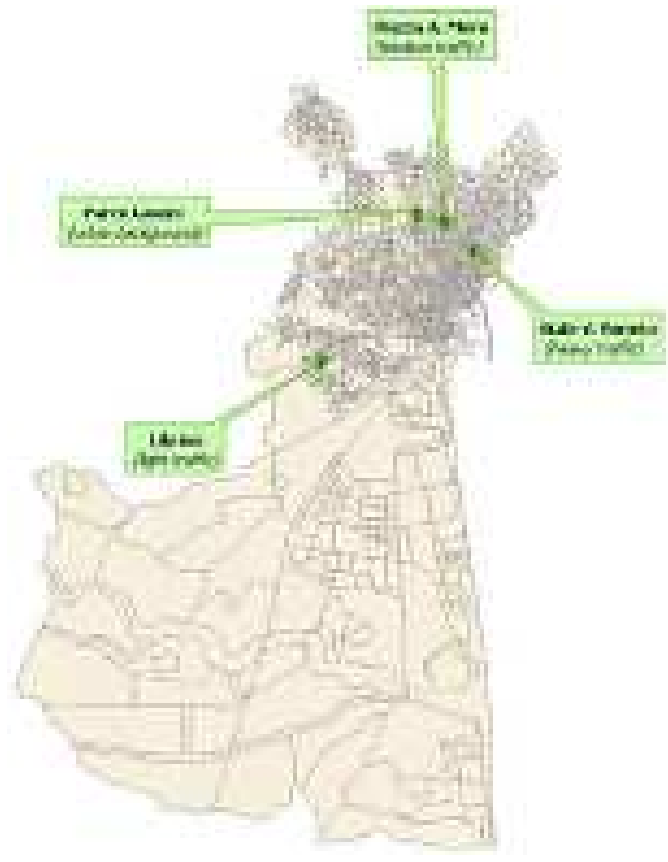

Fig. 1. Map of the city of Catania, Sicilia showing the location of the stations for pollutant concentration.

was deployed in order to assess the environmental condition in the various areas of Catania.

The Direzione Ecologia e Ambiente P.O. Prevenzione Inquinamento of the municipal city of Catania provided four monitoring stations (see Fig. 2) to measure PM10, NO2, $N O, N O x$ concentrations. The concentration data set covered a period of the year 2012 of data samples. The monitoring stations are situated in different areas of the city as shown in the Table I.

This study is based on PM10, $\mathrm{NO}_{2}, \mathrm{NO}, \mathrm{NO} x$ concentrations data collected by Direzione Ecologia e Ambiente P.O. Prevenzione Inquinamento of the municipal city of Catania during a year 2012. The concentrations were collected using an data storage device and electronic spreadsheet handled the data in periods of 23 hours, every day, in agreement with norms established by Directive 2008/50/EC of the European Parliament and of the Council on ambient air quality and cleaner air for Europe. The data set of 864 recorded concentrations contained missing values due to instrument malfunction and calibrations. Therefore we have used the related countermeasures [16] as well as interpolation linear methods to find intermediate points in your data and to calculate the intermediate value. In our study, normalization is required to calibrate data samples. The factors of corrections are represented by scalar multiple that is applied to each data samples, as shown in the Table II

Moreover it is known that the concentration of pollutant atmospheric is strongly related to the meteorological conditions (temperature, humidity, wind, pressure) and other predominant atmospheric condition as UV radiation, clouds and clear-sky effects, intense rainfalls but in this studies, the influence of meteorological conditions in the concentration of air pollutant has been overlooked.
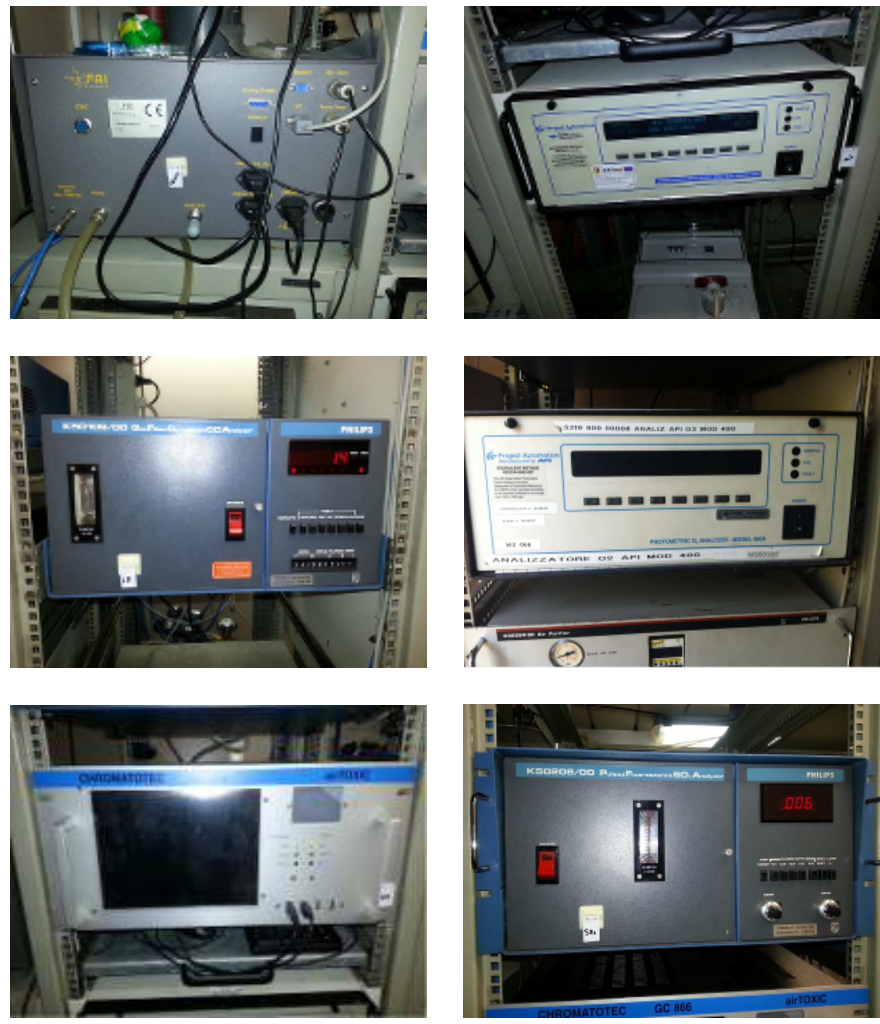

Fig. 2. Equipments used from each monitoring station

\section{The Instrumentations Measurement}

Monitoring networks consist mainly of three stations not including monitoring station of Librino's area insofar as the air pollution impacts from traffic congestion and related air emissions on centre of the city is very limited accordingly it is sidelined as unimportant and therefore negligible. We have achieved two different monitoring stations to forecast the values of third station. We can demonstrate by selecting concentrations of Parco Gioieni and Viale Veneto that it is possible forecasting the other concentration recorded of other station of Moro's area. It acquires data of concentrations of two respectly monitoring stations as input of neural network and the data target are concentrations of third monitoring stations.

An extensive range of gas analyzers and analysis systems are offered for the purpose of area air quality and

TABLE II

\begin{tabular}{cccc}
\multicolumn{4}{c}{ NORMALIZATION FACTORS } \\
\hline Pollutants & Viale V. Veneto & Piazza A. Moro & Parco Gioeni \\
\hline NOx & 119.1025 & 223.0681 & 55.0303 \\
$N O$ & 94.6267 & 102.2157 & 46.8453 \\
$N O_{2}$ & 70.1509 & 121.2491 & 101.7528 \\
$P M 10$ & 59.0360 & 34.6000 & 195.2486 \\
\hline
\end{tabular}




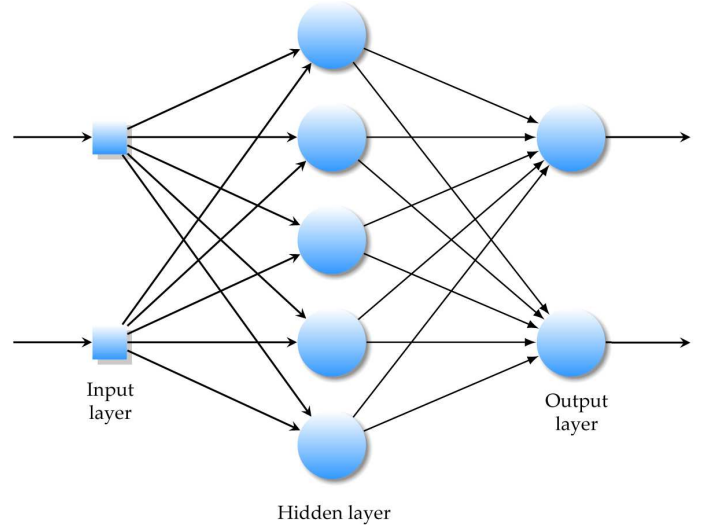

Fig. 3. A multi-layer feed forward ANN with one hidden layers.

safety applications. For the analysis and monitoring of trace amounts of $\mathrm{NO} / \mathrm{NO}_{2} / \mathrm{NO} x$ has been used chemiluminescence $\mathrm{NO} / \mathrm{NO}_{2} / \mathrm{NOx}$ analyzer that uses the proven chemiluminescence detection principle, coupled with state-of-the-art microprocessor technology to provide the sensitivity, stability and ease of use needed for ambient or dilution CEM monitoring requirements. The analyzer uses multi-tasking software which allows complete control of all functions while providing online indication of important operating parameters.

Measurements are automatically compensated for temperature and pressure changes. UNI EN 14211:2005. In the field of the PMx particulate matter sampling and mass measurement, the SWAM 5a Dual channel Monitor provides an extremely accurate and reliable estimation of the average particulate matter mass concentration with simultaneous sampling on two independent lines with associated mass measurement and possibility of drawing samples with different granulometric cut sizes (for example mass measurement reproducibility of PM10 is $10 \mu g$ ).

\section{The Basics of Neural Networks and CFNNS}

In a multi-layer feed forward neural network the artificial neurons are arranged in layers and all the neurons in each layer have connections to all the neurons in the next layer. Associated with each connection between these artificial neurons is defined a weight value to represent the connection weight. Fig. 3 shows a multi-layer feed-forward neural network architecture with an input layer, an output layer, and one hidden layer (e.g. [17], [18]. The operation of the network consists of a forward pass through the network. Each neuron in a layer, other than the input layer, computes first a linear combination of the outputs of the neurons of the previous layer, plus a bias. The coefficients of the linear combinations plus the biases are called the weights. Neurons in the hidden layer are called hidden neurons and then compute a non-linear function, the activation function of their input [19]. The activation functions $f(x)$ of the neurons must be continuously differentiable such that:

$$
\lim _{x \rightarrow-\infty} f(x)=-1, \quad \lim _{x \rightarrow \infty} f(x)=1
$$

In the neural computation literature the activation functions commonly used are: the sigmoid also referred to as the logistic function (2), the hyperbolic tangent sigmoid transfer function (3), the radial basis transfer function (4). While for the output layer, very often, the linear function is used.

$$
\begin{gathered}
f(x)=\frac{1}{1+\exp (-x)} \\
f(x)=\frac{2}{1+\exp \left(-x^{2}\right)} \\
f(x)=\exp \left(-x^{2}\right)
\end{gathered}
$$

One pass over the entire training data set represents a training epoch. The criteria of convergence in training is based on minimizing the mean squared error (MSE) to a level where a satisfactory agreement is found between the training set results and the network result. Once the network is considered to be trained, testing data and validation data set are provided as input it and the outputs are compared with the experimental or observed result. The Cascade forward back propagation Neural Network (CFNN) performed better than the feed forward back propagation algorithm models, especially in reducing the scatter of predictions.

CFNN is similar to the feed-forward networks shown in Fig. 3, but include a weight connection from the input to each layer and from each layer to the successive layers. While feed forward neural networks can potentially learn any input-output relationship the CFNNs with more layers might learn complex relationships more quickly and detailed discussion of this topic can be found in related literature [20], [21].

\section{The Selected CFNN and Simulation Results}

The kind of neural network proposed in this work, as shown in Fig. 4, is a CFNN composed by an input layer, an output layer and two hidden layers: the first hidden layer has six neurons with hyperbolic tangent sigmoid transfer function, the second six neurons with Log-sigmoid transfer function. While for the output layer has been used a linear transfer function.

The network has 8 inputs; there are four pollutants ( $P M 10, \mathrm{NO}_{2}, \mathrm{NO}, \mathrm{NOx}$ ) for each monitoring stations of Viale Veneto and Parco Gioieni, and 4 output which includes the concentrations of Moros area.

For the training of the CFNN were used the data of the 288 hours of the year 2012 and the air pollutant concentrations of the station of Moro's area are predicted using this network. This neural network was trained and validated with trainbfg algorithm (BFGS quasi-Newton backpropagation). In this research, $80 \%$ of the data is used for training of network and $20 \%$ of the data is used for testing the network.

The mean square error of the testing data is 0.0065315 (Fig. 5). In Table III are reported the main simulation results, while in Fig. 6 are depicted the air pollutant concentrations and their predictions in Moro's area. 
TABLE III

DATA ACQUISITION ON 12 FEBRUARY 2012 AND THE PREDICTION FOR 24 HOURS

\begin{tabular}{lllllllllllll}
\hline & \multicolumn{4}{c}{ Viale V. Veneto } & \multicolumn{3}{c}{ Parco Gioeni } & \multicolumn{2}{c}{ Piazza A. Moro } & \multicolumn{2}{c}{ Piazza A. Moro predicted } \\
\hline Time & $N O x$ & $N O$ & $N O_{2}$ & $N O x$ & $N O$ & $N O_{2}$ & $N O x$ & $N O$ & $N O_{2}$ & $N O x$ & $N O$ & $N O_{2}$ \\
\hline 1.00 & 0.24 & 0.11 & 0.35 & 0.17 & 0.05 & 0.31 & 0.26 & 0.02 & 0.44 & 0.24 & 0.00 & 0.40 \\
2.00 & 0.20 & 0.07 & 0.33 & 0.13 & 0.04 & 0.23 & 0.22 & 0.02 & 0.39 & 0.19 & 0.02 & 0.32 \\
3.00 & 0.16 & 0.04 & 0.30 & 0.09 & 0.03 & 0.14 & 0.19 & 0.01 & 0.34 & 0.13 & 0.04 & 0.22 \\
4.00 & 0.12 & 0.03 & 0.22 & 0.07 & 0.02 & 0.08 & 0.11 & 0.00 & 0.20 & 0.09 & 0.04 & 0.13 \\
5.00 & 0.14 & 0.05 & 0.24 & 0.06 & 0.02 & 0.08 & 0.08 & 0.00 & 0.15 & 0.09 & 0.04 & 0.13 \\
6.00 & 0.24 & 0.14 & 0.31 & 0.08 & 0.03 & 0.11 & 0.12 & 0.02 & 0.20 & 0.11 & 0.01 & 0.18 \\
7.00 & 0.42 & 0.30 & 0.42 & 0.08 & 0.02 & 0.12 & 0.14 & 0.02 & 0.24 & 0.11 & 0.04 & 0.21 \\
8.00 & 1.01 & 0.93 & 0.55 & 0.15 & 0.03 & 0.29 & 0.55 & 0.36 & 0.55 & 0.06 & 0.11 & 0.22 \\
9.00 & 0.92 & 0.80 & 0.60 & 0.34 & 0.17 & 0.57 & 0.49 & 0.29 & 0.53 & 0.36 & 0.27 & 0.48 \\
10.00 & 0.61 & 0.46 & 0.53 & 0.21 & 0.08 & 0.38 & 0.33 & 0.12 & 0.44 & 0.29 & 0.10 & 0.38 \\
11.00 & 0.55 & 0.40 & 0.53 & 0.17 & 0.06 & 0.31 & 0.26 & 0.09 & 0.37 & 0.24 & 0.08 & 0.36 \\
12.00 & 0.58 & 0.41 & 0.56 & 0.14 & 0.06 & 0.22 & 0.17 & 0.05 & 0.25 & 0.19 & 0.08 & 0.29 \\
13.00 & 0.49 & 0.33 & 0.52 & 0.09 & 0.04 & 0.11 & 0.13 & 0.03 & 0.20 & 0.11 & 0.05 & 0.20 \\
14.00 & 0.46 & 0.31 & 0.48 & 0.09 & 0.04 & 0.12 & 0.14 & 0.04 & 0.21 & 0.11 & 0.05 & 0.21 \\
15.00 & 0.43 & 0.27 & 0.48 & 0.09 & 0.04 & 0.13 & 0.12 & 0.03 & 0.18 & 0.12 & 0.04 & 0.22 \\
16.00 & 0.46 & 0.30 & 0.50 & 0.08 & 0.03 & 0.12 & 0.13 & 0.03 & 0.21 & 0.11 & 0.04 & 0.21 \\
17.00 & 0.47 & 0.29 & 0.52 & 0.10 & 0.03 & 0.17 & 0.13 & 0.02 & 0.22 & 0.15 & 0.04 & 0.28 \\
18.00 & 0.48 & 0.30 & 0.54 & 0.13 & 0.03 & 0.24 & 0.11 & 0.02 & 0.18 & 0.20 & 0.04 & 0.33 \\
19.00 & 0.55 & 0.36 & 0.59 & 0.08 & 0.02 & 0.14 & 0.17 & 0.02 & 0.28 & 0.12 & 0.04 & 0.24 \\
20.00 & 0.56 & 0.37 & 0.60 & 0.17 & 0.03 & 0.34 & 0.22 & 0.02 & 0.37 & 0.26 & 0.06 & 0.40 \\
21.00 & 0.52 & 0.34 & 0.56 & 0.24 & 0.05 & 0.52 & 0.18 & 0.02 & 0.31 & 0.35 & 0.06 & 0.48 \\
22.00 & 0.32 & 0.16 & 0.43 & 0.09 & 0.02 & 0.14 & 0.10 & 0.01 & 0.17 & 0.13 & 0.01 & 0.24 \\
23.00 & 0.37 & 0.20 & 0.49 & 0.08 & 0.02 & 0.12 & 0.18 & 0.01 & 0.31 & 0.11 & 0.00 & 0.23 \\
24.00 & 0.41 & 0.21 & 0.56 & 0.09 & 0.02 & 0.14 & 0.23 & 0.02 & 0.41 & 0.13 & 0.01 & 0.26 \\
\hline
\end{tabular}

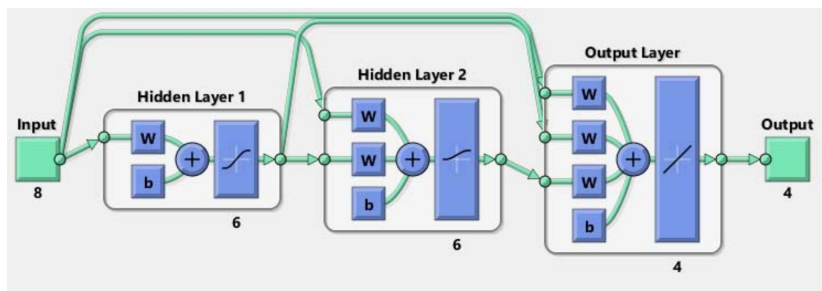

Fig. 4. The selected network topology for predict the air pollutant concentrations in Moro's area.

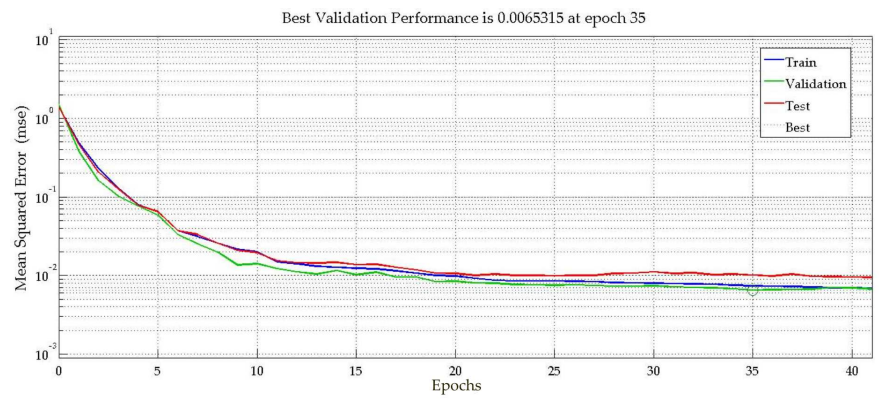

Fig. 5. Performance of the NN.

\section{CONCLUSION AND DisCUSSION}

PM10, $\mathrm{NO}_{2}, \mathrm{NO}, \mathrm{NOx}$ constitute the major concern for air quality of Catania. This paper addresses the problem of modeling such air pollutants in a single station of measurement by CFNNs, currently recognized as an effective approach to the end of air quality evaluation, exploiting data coming from other stations near located.

In the last years, neural approaches have been recognized to constitute a viable alternative to this problems and in particular static neural networks. In our study we have taken into account the concentrations of air pollution of two different monitoring stations located in Parco Gioeni and Viale Vittorio Veneto to estimate the concentrations of a third station, in the site of Piazza Moro, with the same operative conditions,

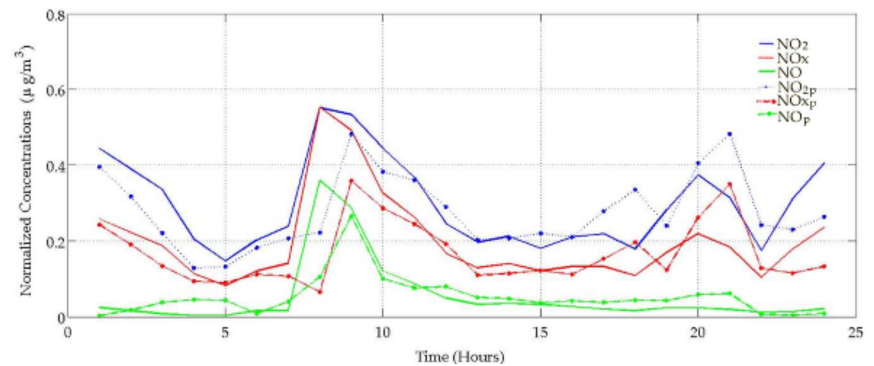

Fig. 6. The air pollutant concentrations and their predictions in Moro's area

orographic effect, traffic congestion, buildings and materials. To take advantage of more virtual monitoring stations can also facilitate the process of validation and consistency of the data recorded in the real monitoring stations.

The proposed approach is very powerful to reduce instrumentation equipment and a large number of monitoring stations, according the European Directives 2008/50/EC so as evidenced by Legislative Decree No $155 / 2010$ due to their expensive maintenance/repair. This method also helps Public Authorities for planning to decrease the public transports and private vehicles in the case of particular meteorological conditions. The approach is also valuable because data sets suffer from periods of missing data caused by instrumentation failures of measurement stations. These CFNN based models use the pollution data from other stations and in the future will enclose also meteorological information.

\section{REFERENCES}

[1] C. Napoli, G. Pappalardo, E. Tramontana, Z. Marszałek, D. Połap, and M. Woźniak, "Simplified firefly algorithm for 2d image key-points search," in Symposium on Computational Intelligence for Humanlike Intelligence (CHILI), ser. Symposium Series on Computational Intelligence (SSCI). IEEE, 2014, pp. 118-125. [Online]. Available: http://dx.doi.org/10.1109/CIHLI.2014.7013395

[2] M. Woźniak, D. Połap, M. Gabryel, R. Nowicki, C. Napoli, and E. Tramontana, "Can we process $2 \mathrm{~d}$ images using artificial bee colony?" in Artificial Intelligence and Soft Computing, ser. Lecture Notes in 
Computer Science. Springer International Publishing, 2015, vol. 9119, pp. 660-671, doi: 10.1007/978-3-319-19324-3_59.

[3] D. Polap, M. Wozniak, C. Napoli, E. Tramontana, and R. Damasevicius, "Is the colony of ants able to recognize graphic objects?" in Information and Software Technologies, ser. Communications in Computer and Information Science, G. Dregvaite and R. Damasevicius, Eds. Springer International Publishing, 2015, vol. 538, pp. 376-387, doi: 10.1007/9783-319-24770-0_33.

[4] F. Bonanno, G. Capizzi, G. Lo Sciuto, C. Napoli, G. Pappalardo, and E. Tramontana, "A novel cloud-distributed toolbox for optimal energy dispatch management from renewables in igss by using wrnn predictors and gpu parallel solutions," in International Symposium on Power Electronics, Electrical Drives, Automation and Motion (SPEEDAM). IEEE, 2014, pp. 1077-1084. [Online]. Available: http://dx.doi.org/10.1109/SPEEDAM.2014.6872127

[5] C. Napoli, G. Pappalardo, and E. Tramontana, "An agent-driven semantical identifier using radial basis neural networks and reinforcement learning," in XV Workshop From Objects to Agents (WOA), vol. 1260 Catania, Italy: CEUR-WS, September 2014.

[6] K. Y. Chan and L. Jian, "Identification of significant factors for air pollution levels using a neural network based knowledge discovery system," Neurocomputing, vol. 99, pp. 564-569, 2013.

[7] C. Ho, A. Knudby, P. Sirovyak, Y. Xu, M. Hodul, and S. B. Henderson, "Mapping maximum urban air temperature on hot summer days," Remote Sensing of Environment, vol. 154, pp. 38-45, 2014.

[8] T. Alhanafy, F. Zaghlool, and A. El Din Moustafa, "Neuro fuzzy modeling scheme for the prediction of air pollution," Journal of American Science, vol. 6, no. 12, pp. 605-616, 2010.

[9] J. Hooyberghs, C. Mensink, G. Dumont, F. Fierens, and O. Brasseur, "A neural network forecast for daily average pm10 concentrations in belgium," Atmospheric Environment, vol. 39, no. 18, pp. 3279-3289, 2005.

[10] V. R. Prybutok, J. Yi, and D. Mitchell, "Comparison of neural network models with arima and regression models for prediction of houston's daily maximum ozone concentrations," European Journal of Operational Research, vol. 122, no. 1, pp. 31-40, 2000.

[11] J. Kukkonen, L. Partanen, A. Karppinen, J. Ruuskanen, H. Junninen, M. Kolehmainen, H. Niska, S. Dorling, T. Chatterton, R. Foxall, and G. Cawley, "Extensive evaluation of neural network models for the prediction of no 2 and pm10 concentrations, compared with a deterministic modelling system and measurements in central helsinki," Atmospheric Environment, vol. 37, no. 32, pp. 4539-4550, 2003.

[12] H. Junninen, H. Niska, K. Tuppurainen, J. Ruuskanen, and M. Kolehmainen, "Methods for imputation of missing values in air quality data sets," Atmospheric Environment, vol. 38, no. 18, pp. 8952907, 2004

[13] M. Gardner and S. Dorling, "Neural network modelling and prediction of hourly nox and no2 concentrations in urban air in london," Atmospheric Environment, vol. 33, no. 5, pp. 709-719, 1999

[14] F. Bonanno, G. Capizzi, G. Lo Sciuto, C. Napoli, G. Pappalardo, and E. Tramontana, "A cascade neural network architecture investigating surface plasmon polaritons propagation for thin metals in openmp," in Proceedings of International Conference on Artificial Intelligence and Soft Computing (ICAISC), ser. Springer LNCS, vol. 8467, Zakopane, Poland, June 2014, pp. 22-33.

[15] F. Bonanno, G. Capizzi, S. Coco, C. Napoli, A. Laudani, and G. Lo Sciuto, "Optimal thicknesses determination in a multilayer structure to improve the spp efficiency for photovoltaic devices by an hybrid fem-cascade neural network based approach," in Proceedings of IEEE International Symposium on Power Electronics, Electrical Drives, Automation and Motion (SPEEDAM), Ischia, Italy, June 2014, pp. 355-362.

[16] B. Nowak, R. Nowicki, M. Woźniak, and C. Napoli, "Multi-class nearest neighbour classifier for incomplete data handling," in Artificial Intelligence and Soft Computing, ser. Lecture Notes in Computer Science. Springer International Publishing, 2015, vol. 9119, pp. 469-480, doi: 10.1007/978-3-319-19324-3 42.

[17] C. Napoli, G. Pappalardo, E. Tramontana, R. Nowicki, J. Starczewski, and M. Woźniak, "Toward work groups classification based on probabilistic neural network approach," in Artificial Intelligence and Soft Computing, ser. Lecture Notes in Computer Science. Springer International Publishing, 2015, vol. 9119, pp. 79-89, doi: 10.1007/978-3-31919324-3_8.

[18] M. Wozniak, D. Polap, R. K. Nowicki, C. Napoli, G. Pappalardo, and E. Tramontana, "Novel approach toward medical signals classifier" in International Joint Conference on Neural Networks (IJCNN). IEEE 2015, pp. 1924-1930, doi: 10.1109/IJCNN.2015.7280556.

[19] C. Napoli and E. Tramontana, "An object-oriented neural network toolbox based on design patterns," in Information and Software Technologies, ser. Communications in Computer and Information Science, G. Dregvaite and R. Damasevicius, Eds. Springer International Publishing, 2015, vol. 538, pp. 388-399, doi: 10.1007/978-3-319-24770-0_34.

[20] S. O. Haykin, Neural Networks and Learning Machines. Upper Saddle River, New Jersery 07458: Prentice Hall, 2009 (3rd Edition).

[21] M. Wozniak, C. Napoli, E. Tramontana, and G. Capizzi, "A multiscale image compressor with rbfnn and discrete wavelet decomposition," in International Joint Conference on Neural Networks (IJCNN). IEEE, 2015, pp. 1219-1225, doi: 10.1109/IJCNN.2015.7280461. 